\title{
DETERMINATION OF SELENIUM BY ICP-MS AND HG-ICP-MS IN COAL, FLY ASHES AND SORBENTS USED FOR FLUE GAS CLEANING
}

\author{
Mercedes Díaz-Somoano, M. Antonia López-Antón and \\ M. Rosa Martínez-Tarazona* \\ Instituto Nacional del Carbón (CSIC). C/ Francisco Pintado Fé No 26, 33011, Oviedo, \\ Spain \\ *rmtarazona@,incar.csic.es
}

\begin{abstract}
Selenium is an element of environmental concern which content in coal is generally lower than $2 \mathrm{mg} \mathrm{g}^{-1}$. During coal utilization for power generation this element may be emitted in gas phase or condensed in the particulate matter. To avoid the problems originated by such emissions different systems are being developed to retain selenium compounds in the system using solid sorbents. In this work, the determination of selenium in a variety of solid materials related with the use of coal for energy production was evaluated by two methods; ICP-MS and HG-ICP-MS. Coals, fly ashes and various solids used as sorbents in gas cleaning processes (kaolin, limestone, alumina, metal oxide mixtures and activated carbons), were the materials analyzed. In some of these materials, selenium can be determined with similar results by either method. However in coal, fly ashes and some activated carbons, the use of a HG-ICPMS is necessary to avoid interferences. The results obtained by both methods in samples whose selenium content ranges from $\mu \mathrm{g} \mathrm{g}^{-1}$ to $\mathrm{mg} \mathrm{g}^{-1}$, are discussed. In general, good $( \pm 2-4 \%)$ to excellent $( \pm 1-2 \%)$ agreement between the reference and the obtained concentrations was achieved in the analysis of certified and reference samples. The
\end{abstract}


precision of the analysis, including instrumental, sample preparation and sample homogeneity uncertainties was evaluated, the relative standard deviation (RSD) being lower than $10 \%$ in all cases.

KEYWORDS: selenium determination, microwave digestion, ICP-MS, HG-ICP-MS, coal, fly ashes, solid sorbents.

\section{INTRODUCTION}

Selenium is one of the most volatile trace elements of environmental concern present in coal, its content commonly ranging between 0.2 and $1.4 \mu \mathrm{g} \mathrm{g}^{-1}$ [1]. During coal combustion and gasification, selenium compounds evaporate or condense on the smallest fly ash particles, and are emitted with flue gases into the environment in different proportions. Various methods are under study to reduce these emissions, retention on solid sorbents being one of the most promising. Clay minerals, limestone, fly ashes and metal oxide mixtures are being tested as sorbents for gas cleaning at high temperatures (between 350 and $750^{\circ} \mathrm{C}$ ) [2-4], whereas activated carbons are being examined for the capture of selenium at the lowest $\left(<200^{\circ} \mathrm{C}\right)$ [5]. Maximum retention capacities in these materials range between 1 and $60 \mathrm{mg} \mathrm{g}^{-1}$ depending not only on the characteristics of the sorbent but also on sorption conditions [6]. The successful development and setting up of a gas cleaning process implies monitoring the quantity of selenium retained. Moreover, the correct evaluation of the selenium content in the coal and of that retained in the ashes and sorbents will make it possible to estimate the levels of selenium finally emitted into the environment. Consequently, a sensitive and accurate method for selenium analysis in coal, coal ashes and sorbents is required. 
Before choosing an adequate method, three important points should be borne in mind. One is the wide range of selenium concentrations in the different samples to be analysed ranging from $\mu \mathrm{g} \mathrm{g}^{-1}$ to $\mathrm{mg} \mathrm{g}^{-1}$. The second is the different characteristics of the samples. In one site, some of the sorbents are $100 \% \mathrm{~m} / \mathrm{m}$ mineral matter containing more than $75 \% \mathrm{~m} / \mathrm{m}$ of silica while in other activated carbons contain more than $75 \%$ $\mathrm{m} / \mathrm{m}$ of organic matter. Between these two extremes some samples such as coals, are made up of both organic and mineral matter in different proportions. The third consideration concerns the different modes of occurrence of selenium in the samples. Although in most cases selenium will be present in the form of a $\mathrm{HNO}_{3}$ soluble compound (adsorbed selenium, or selenium sulphides), exceptionally it may also be present in clays [1] or as a glassy solution in fly ashes. In order to analyse these heterogeneous materials, dissolution methods, capable of dissolving selenium in a variety of samples, and precise and accurate methods for selenium determination, are necessary.

A number of fast and efficient acid decomposition procedures, which make use of microwave ovens have already been published for coal, ashes and geological samples [6-12]. In this work, two methods were developed. One of them was applied to kaolin, limestone, alumina, fly ashes, and metal oxides, all of which were mixed with sand as in the sorption experiments, while the other was applied to coals and activated carbons.

The analysis of selenium in solution can be carried out by different procedures. AAS hydride generation is the most widely used for low concentrations [13-15], but ICP-MS may also give good results with the important advantage that it is a multielemental technique $[7-12,16]$. Using ICP-MS, a simultaneous analysis of other volatile trace elements retained in the sorbents, can be carried out. Moreover, this sensitive method can also be used for relatively high concentrations. However, the use 
of ICP-MS for the determination of selenium has its limitations. Selenium is weakly ionised in argon plasma and most of the six selenium isotopes $\left({ }^{74} \mathrm{Se} 0.89 \%\right.$; ${ }^{76} \mathrm{Se} 9.36 \%$; ${ }^{77} \mathrm{Se} 7.63 \% ;{ }^{78} \mathrm{Se} 23.78 \% ;{ }^{80} \mathrm{Se} 49.61 \%$ y ${ }^{82} \mathrm{Se} 8.73 \%$ ), undergo significant isobaric or polyatomic interferences, the most important being $\mathrm{Ar}_{2}$ in 76,78 and 80 masses. $\mathrm{ArCl}$ interference is possible in chlorine matrices when ${ }^{77} \mathrm{Se}$ is used while ${ }^{82} \mathrm{Se}$, the most suitable isotope for selenium quantification, suffers $\mathrm{BrH}$ interference in matrices containing Br. Because the relative proportions of chlorine and bromine in the samples studied in this work are low, the selenium analysis was checked using the less abundant isotopes ${ }^{77} \mathrm{Se}$ and ${ }^{82} \mathrm{Se}$. However the presence, in some of the samples, of elements such as $\mathrm{Zn}, \mathrm{Sm}$ and Dy, that form $\mathrm{Sm}^{2+}$, Dy ${ }^{2+}$ and $\mathrm{Zn}-\mathrm{O}$ in the plasma, interfered with the determination of the ${ }^{77} \mathrm{Se}$ and ${ }^{82} \mathrm{Se}$ isotopes. Another collateral problem in the analysis of some of the samples studied was their relatively high sulphur content, which forms $\mathrm{H}_{2} \mathrm{SO}_{4}$, in the acidic solution, causing deterioration of the $\mathrm{Ni}$ and $\mathrm{Cu}$ interfaces in the equipment. To avoid these problems, the hydride generation method coupled with the ICP-MS technique (HG-ICP-MS) [17-19] was used and compared with the direct ICP-MS method.

\section{EXPERIMENTAL}

The materials used as sorbents at high temperature were: kaolin (K), limestone (L), coal fly ashes (FA), $\gamma$-alumina (A), and the metal oxide mixtures containing spinels; $\mathrm{Zn}_{2} \mathrm{TiO}_{4}$ $(\mathrm{ZT})$, and $\mathrm{ZnFe}_{2} \mathrm{O}_{4}(\mathrm{ZF})$. The $\mathrm{ZT}$ and $\mathrm{ZF}$ samples were prepared by calcination of mixtures of commercial $\mathrm{ZnO}, \mathrm{Fe}_{2} \mathrm{O}_{3}$ and $\mathrm{TiO}_{2}$ at $1100^{\circ} \mathrm{C}$. All these sorbents were used in sorption experiments [8] and were mixed with sand in the proportion of $1+3$, sorbent + sand. Before digestion they were thoroughly homogenised and ground in a Retsch Spectro Mill. The activated carbons used for gas cleaning at low temperature 
were Norit. RBHG3 and Norit. RB3. RBHG3 contains about $6 \% \mathrm{~m} / \mathrm{m}$ of a sulphur compound.

Five reference materials of similar characteristics to the sorbents were used in this work. The high-selenium content reference sample (ASe) and the activated carbon reference samples (ACSe1 and ACSe2), were not standard samples and were prepared specifically for this study. These reference samples were necessary because of the lack of standard samples with similar characteristics to the inorganic sorbents with high selenium concentrations, and because there are no standard activated carbons with certified selenium contents. The reference materials were obtained by adding a known amount of selenium to finely ground alumina (ASe) and to the activated carbons RBHG3 (ACSe1) and RB3 (ACSe2) by dropping a solution of a selenium salt in such a way that the quantity of solution is the exact amount necessary to fill the porous structure of the material. The concentration of selenium in solution was calculated so as to obtain $0.75 \mathrm{mg}$ of selenium per g of sample in ASe and 17.3 and $19.5 \mu \mathrm{g}$ of selenium per $\mathrm{g}$ of sample in $\mathrm{ACSe} 1$ and $\mathrm{ACSe} 2$ respectively. After impregnation, the sample was dried at a temperature lower than $40^{\circ} \mathrm{C}$. The standard samples, were the certified NIST SRM coal fly ash $1633 \mathrm{a}\left(10.3 \mu \mathrm{g} \mathrm{g}^{-1}\right.$ of selenium $)$ and the NIST SARM-20 coal $(0.8 \mu \mathrm{g}$ $\mathrm{g}^{-1}$ of selenium). To include all the possible variables in the uncertainty of the results the reference materials ASe and SRM 1633a were mixed and homogenised with sand in the same proportion as the sorbents are used in some retention experiments [6], and the mixture was ground before dissolution and analysis. The coal and the activated carbons were just ground.

Sample digestion was carried out in a microwave oven (Milestone MLS 1200) fitted with an EMS exhaust unit and a microprocessor to control the power. Teflon 
high-pressure digestion vessels (HPV80) were used. Six vessels were placed in the oven simultaneously.

Sample dissolution was carried out in a different way for the samples enriched in inorganic and organic matter. For inorganic materials and minerals about $0.100 \mathrm{~g}$ of sample was digested. Because the size of the sample to be dissolved is of critical importance, digestion with different particle sizes was tested. It was found that the best results were obtained by grinding the sorbent + sand mixture to a size close to $50 \mu \mathrm{m}$. An acid mixture capable of completely dissolving all sorbents containing silica was selected after testing, its composition being $2 \mathrm{ml}$ of $\mathrm{HNO}_{3} 65 \%, 4 \mathrm{ml}$ of $\mathrm{HF} 40 \%$ and 5 ml of saturated $\mathrm{H}_{3} \mathrm{BO}_{3}$. Boric acid was added after dissolution to neutralise the corrosive hydrofluoric. The digestion program is described in Table 1.

Table 1.- Instrumental parameters for the determination of selenium by ICP-MS

\begin{tabular}{ll|ll}
\hline \multicolumn{2}{l|}{ Inductively Coupled Plasma } & \multicolumn{2}{|l}{ Mass spectrometer } \\
\hline RF Power & $1200 \mathrm{w}$ & Sampling cone & $\mathrm{Ni}$ \\
Carrier Gas & $1.271 \mathrm{~min}^{-1}$ & Skimmer cone & $\mathrm{Ni}$ \\
Plasma Gas & $15.01 \mathrm{~min}^{-1}$ & Data acquisition & 3 points per mass \\
Auxiliary Gas & $1.01 \mathrm{~min}^{-1}$ & Integration time & $0.10 \mathrm{~s}$ per point \\
Sample Depth & $5.6 \mathrm{~mm}$ & Acquisitions & 5 \\
Peri-pump & $0.1 \mathrm{rpm}$ & Isotopes measured & ${ }^{82} \mathrm{Se}$ and ${ }^{103} \mathrm{Rh}$ \\
Nebuliser & Babington & & \\
\hline
\end{tabular}

The selenium present in the coal and the retained in the activated carbons was extracted by using $7.5 \mathrm{ml}$ of suprapur $\mathrm{HNO}_{3} 65 \%$, which was added to $50 \mathrm{mg}$ of sample (ground to $50 \mu \mathrm{m}$ ) in closed Teflon vessels. The microwave program consisted in subjecting the sample to a power of $600 \mathrm{w}$ for $6 \mathrm{~min}$. After the vessels were cooled, the samples were filtered. 
Table 2- Instrumental parameters for the determination of selenium by HG-ICP-MS.

\begin{tabular}{|c|c|}
\hline \multicolumn{2}{|l|}{ Hydride generator } \\
\hline $\mathrm{NaBH}_{4}$ & $1 \% / \mathrm{NaOH}$ \\
\hline Acid Concentration & $\mathrm{HCl} 1.6 \mathrm{M}$ \\
\hline \multicolumn{2}{|c|}{ Inductively Coupled Plasma } \\
\hline RF Power & $1200 \mathrm{w}$ \\
\hline Carrier Gas & $1.201 \mathrm{~min}^{-1}$ \\
\hline Plasma Gas & $15.01 \mathrm{~min}^{-1}$ \\
\hline Auxiliary Gas & $0.601 \mathrm{~min}^{-1}$ \\
\hline Sample Depth & $5.6 \mathrm{~mm}$ \\
\hline \multicolumn{2}{|c|}{ Mass spectrometer (As described in Table 1) } \\
\hline
\end{tabular}

The analysis of selenium in solution was carried out by ICP-MS and HG-ICP-MS. The ICP-MS equipment was an HP 4500 and the operating parameters used are listed in Tables 2 and 3. Instrumental conditions were optimised using a tune solution containing $10 \mathrm{ppb}$ of ${ }^{7} \mathrm{Li},{ }^{89} \mathrm{Y},{ }^{140} \mathrm{Ce}$ and ${ }^{205} \mathrm{Tl}$. The solution obtained by the microwave dissolution method was diluted to $50 \mathrm{ml}$. For ICP-MS conventional analysis, an aliquot (between 100 and $500 \mu \mathrm{l}$ ) of this solution and $100 \mu \mathrm{l}$ of a $1 \mu \mathrm{g} \mathrm{ml} \mathrm{m}^{-1}$ solution of the internal standard $\left({ }^{103} \mathrm{Rh}\right)$ were taken to $10 \mathrm{ml}$. The internal standard was used in order to compensate the instrumental drift while standard additions were used to compensate matrix interferences. In another hand, to determine selenium by HG-ICP-MS, and to obtain the necessary acidity for the formation of the hydride, $1.5 \mathrm{ml}$ of $\mathrm{HCl} 30 \%$ was added to an aliquot of $8.5 \mathrm{ml}$ of the solution from the microwave digestion, resulting a final volume of $10 \mathrm{ml}$. In this case $10 \mathrm{ppb}$ of rhodium were added too, in order to compensate the signal drift. The spray chamber was used as gas-liquid separator. ${ }^{17}$ The system set-up consisted in connecting the sample and the reducing agent $\left(\mathrm{NaBH}_{4}\right)$ with a Y-type connector and rotating the nebulizer (babintong) $180^{\circ}$ (Figure 1). The mixed solution was introduced into the nebuliser, and the hydride formed was transferred into 
the plasma to be ionised. Conditions for hydride generation were optimised and selenium determination was optimised to the indicated in Table 3.

Table 3.- Microwave digestion program for samples containing silica.

\begin{tabular}{c|c}
\hline \multicolumn{2}{l}{ Stage 1: $\mathrm{HNO}_{3}+\mathbf{H F}$} \\
\hline Time (min) & Power $(w)$ \\
8 & 300 \\
4 & 600 \\
5 & 450 \\
5 & Vent.
\end{tabular}

\begin{tabular}{c|c}
\hline Stage 2: $\mathbf{H}_{3} \mathbf{B O}_{3}$ & \\
\hline Time (min) & Power (w) \\
6 & 600 \\
3 & Vent. \\
\hline
\end{tabular}

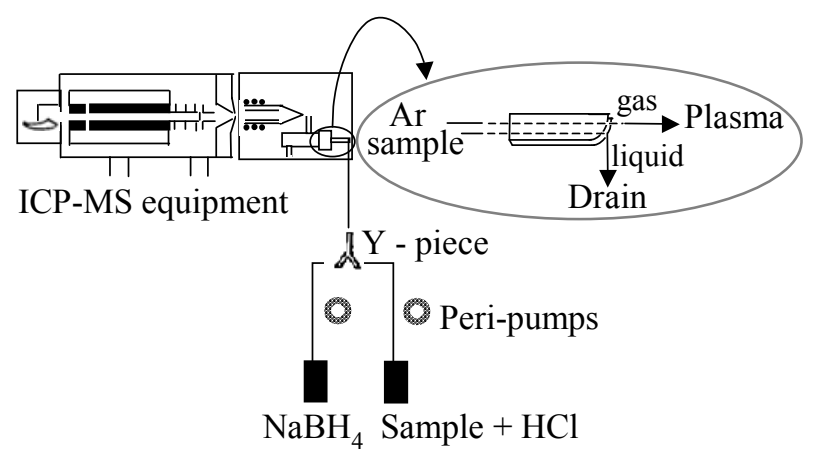

Hydride generator

Figure 1. Diagram of the HG-ICP-MS system.

\section{RESULTS AND DISCUSSION}

For conventional ICP-MS, the quantification method was selected from results obtained for the analysis by external calibration and standard additions of solutions with a known concentration of selenium $(10 \mathrm{ppb})$ in the different matrices. In this way, matrix effects 
for various matrices, that were compensate with the standard addition method, were observed. Plotting the slope ratio of the lines obtained for acid calibration (Ac) and standard additions (Ad) the presence of these matrix effects could be corroborated (Figure 2). The slope ratios obtained for the different matrices are quite different from 1, ranged between 0.6 and 0.8. By HG-ICP-MS the hydride formed is separated $(95 \%$ efficiency for the system used) from the sample so matrix effects are minimised and external calibration is an appropriate quantification method for selenium determination.

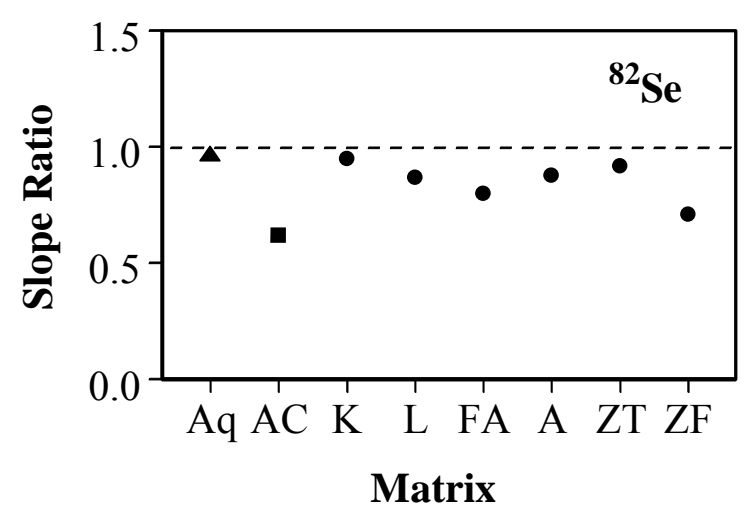

Figure 2.- Ratios between the slopes obtained by external calibration with acid and aqueous solutions $(\boldsymbol{\Delta})$ and between the slopes obtained by standard addition and calibration in the problem solution (घ). AC; Activated Carbon; K; Kaolin, L; Limestone, F.A.; Fly Ashes, A; Alumina, ZT and ZF; metal oxide mixtures).

The reference and standard materials were employed throughout the work to provide data quality assurance. After a preliminary study in which the determination of selenium was evaluated comparatively, using ${ }^{77} \mathrm{Se}$ and ${ }^{82} \mathrm{Se}$ in the samples, ${ }^{82} \mathrm{Se}$ was chosen for the analysis. It was not possible to analyse the certified standards $1633 \mathrm{a}$ and SARM 20 by ICP-MS, because of their complex matrix and high zinc content $(220 \mu \mathrm{g}$ $\mathrm{g}^{-1}$ and $17 \mu \mathrm{g} \mathrm{g}^{-1}$ respectively), the $\mathrm{Zn} / \mathrm{Se}$ ratio being close to 21 in both cases. The 
reference sample ASe, whose selenium content is in the order of $\mathrm{mg} \mathrm{g}^{-1}$, and the ACSe2, whose selenium content is in the order of $\mu \mathrm{g} \mathrm{g}^{-1}$, were used to validate the method. All the reference materials and standard samples were analysed by HG-ICP-MS.

The accuracy and precision of the results obtained were evaluated. As can be seen (Tables 4-5) good $( \pm 2-4 \%)$ to excellent $( \pm 1-2 \%)$ agreement was achieved between the certified or reference values and those obtained by the methods studied. The

Table 4.- Results of selenium determination by ICP-MS in reference samples

\begin{tabular}{l|c|c}
\hline \multicolumn{3}{c}{ ICP-MS } \\
\hline Parameter & $A S e\left(m g g^{-1}\right)$ & $A C S e 2\left(\mu g g^{-1}\right)$ \\
\hline $\mathrm{n}$ & 11 & 11 \\
$\mathrm{SD}_{\text {Total }}$ & 0.08 & 0.76 \\
$\mathrm{SD}_{\text {Instr }}$ & 0.04 & 0.58 \\
$\mathrm{SD}_{\mathrm{SP}}$ & 0.07 & 0.49 \\
$\mathrm{X}_{\text {reference }}$ & 0.75 & 19.5 \\
$\bar{X}$ & 0.77 & 19.1 \\
$\%$ RSD & 10.4 & 4.0 \\
\hline
\end{tabular}

$\mathrm{n}$; number of replicates, $\mathrm{SD}_{\text {tot }}$; standard deviation of the analysis, $\mathrm{SD}_{\text {int }}$; standard deviation of the instrument, $\mathrm{SD}_{\mathrm{sp}}$; standard deviation of sample preparation, $\mathrm{X}_{\text {reference, }}$ certified or added concentration, $\overline{\mathrm{X}}$; average value, \%RSD; relative standard deviation.

Table 5 .- Results of selenium determination by HG-ICP-MS in reference samples

\begin{tabular}{l|c|c|c|c|c}
\hline \multicolumn{5}{c}{ HG-ICP-MS } \\
\hline \multirow{2}{*}{ Parameter } & \multicolumn{5}{c}{$\mu g g^{-1}$} \\
\cline { 2 - 6 } & $A C S e 1$ & $A C S e 2$ & SARM 20 & $1633 a$ & $A S g^{-1}$ \\
\hline$S D_{\text {Total }}$ & 1.45 & 1.33 & 0.08 & 0.96 & 0.07 \\
$S D_{\text {Inst. }}$ & 0.96 & 0.92 & 0.06 & 0.60 & 0.02 \\
$S D_{S P}$ & 1.09 & 0.96 & 0.05 & 0.75 & 0.06 \\
$X_{\text {reference }}$ & 17.3 & 19.5 & 0.80 & 10.3 & 0.75 \\
$\bar{X}$ & 17.0 & 18.7 & 0.83 & 10.1 & 0.71 \\
$\%$ RSD & 9.06 & 6.68 & 9.64 & 9.50 & 9.86 \\
\hline
\end{tabular}


precision of the analysis was considered as being due to two independent sources of error, the uncertainty in the sample preparation procedure and instrumental precision. Calculations are based on equation (1) [14], in which $\mathrm{SD}_{\mathrm{SP}}$ is the uncertainty in the sample preparation procedure; $\mathrm{SD}_{\text {Total }}$ analytical precision and $\mathrm{SD}_{\text {Instr }}$ instrumental precision.

$$
\left(\mathrm{SD}_{\text {Total }}\right)^{2}=\left(\mathrm{SD}_{\mathrm{SP}}\right)^{2}+\left(\mathrm{SD}_{\text {Instr }}\right)^{2}
$$

$\mathrm{SD}_{\text {Total }}$ was evaluated by analysing fifteen replicate samples of the mentioned reference materials. Then averages $\mathrm{x}$, standard deviations SD and relative standard deviations $(\% \mathrm{RSD})$ were calculated. Repeatability of instrumental measurements $\left(\mathrm{SD}_{\text {Instr }}\right)$ was tested by analysing one of the above mentioned solutions fifteen times. Tables 5-6 give the values of these parameters for the standard and reference samples. It should be borne in mind that in the reference material (not certified standards), the uncertainty of the results also includes the homogeneity of the incipient wetness procedure used to impregnate the solid with selenium.

Table 4 shows the results of the analysis of selenium by direct ICP-MS for the samples $\mathrm{ASe}$ and $\mathrm{ACSe} 2$, in which the elements that may produce interferences are minimum. In these samples, results obtained were statistically indistinguishable from the reference values with absolute error ranging between $2-3 \%$ and an RSD of 10 and $4 \%$ respectively.

The results obtained by HG-ICP-MS for all the reference materials are given in Table 5. In all cases relative standard deviations are lower than $10 \%$ for 15 replicates, and the differences between the reference or certified values and the results obtained were below 5\%. It can be observed (Tables 4-5) that the sample preparation uncertainty obtained in the analysis is similar to instrumental uncertainty, a similar contribution being made in all cases to total uncertainty. In general, the values obtained for the 
instrumental uncertainty by HG-ICP-MS are higher than those obtained by ICP-MS due to the instability observed in the argon plasma as a result of hydrogen excess produced during hydride generation.

Uncertainty was also estimated by using samples with different unknown concentrations of selenium. The samples analysed were sorbents obtained after performing sorption experiments in which conditions varied, as a consequence of which the concentration in each sample was different. Table 6 shows the results obtained from each sample as the average of 5 determinations. Generally speaking, standard deviation does not depend on the nature of the sample analysed and relative standard deviations for 5 determinations are lower than $16 \%$ in most cases. The uncertainty of the results is due not only to the uncertainty of the analytical method, determined by the reference materials (Tables 4-5), but also to the variations in the retention experiment and the unhomogeneity of the sorbent bed.

Table 6.- Average values obtained for $n=5$ replicates in samples of sorbents containing different quantities of selenium after sorption experiments.

\begin{tabular}{|c|c|c|c|c|c|c|c|}
\hline Sample & $m g S e g^{-1}$ & $S D$ & $R S D$ & Sample & $m g S e g^{-1}$ & $S D$ & $R S D$ \\
\hline $\mathrm{K}(1)$ & 4.04 & 0.66 & 16.0 & $\mathrm{~A}(1)$ & 1.10 & 0.18 & 16.4 \\
\hline $\mathrm{K}(2)$ & 5.62 & 0.35 & 6.23 & $\mathrm{~A}(2)$ & 1.28 & 0.14 & 10.9 \\
\hline $\mathrm{K}(3)$ & 6.06 & 0.97 & 16.0 & $\mathrm{~A}(3)$ & 1.09 & 0.12 & 11.0 \\
\hline $\mathrm{L}(1)$ & 50.7 & 4.28 & 8.44 & $\mathrm{ZT}(1)$ & 39.7 & 2.18 & 5.49 \\
\hline $\mathrm{L}(2)$ & 43.0 & 5.33 & 12.0 & $\mathrm{ZT}(2)$ & 59.9 & 2.24 & 3.74 \\
\hline $\mathrm{L}(3)$ & 65.9 & 4.88 & 7.40 & $\mathrm{ZT}(3)$ & 58.4 & 3.13 & 5.36 \\
\hline FA(1) & 25.0 & 3.10 & 12.4 & ZFT(1) & 21.8 & 3.99 & 18.3 \\
\hline $\mathrm{FA}(2)$ & 25.8 & 3.72 & 14.4 & $\mathrm{ZFT}(2)$ & 37.7 & 3.85 & 10.2 \\
\hline $\mathrm{FA}(3)$ & 25.4 & 1.77 & 6.97 & ZFT(3) & 54.3 & 6.24 & 11.5 \\
\hline
\end{tabular}

K; Kaolin, L; Limestone, FA; Fly ashes, A; Alumina and ZT and ZF; metal oxide mixtures (all mixed with sand). 


\section{ACKNOWLEDGEMENTS}

This work was carried out with financial support from ECSC (7220-ED/069 and 722ED/095 projects).

\section{REFERENCES}

1 Swaine D.J., Trace Elements in Coal, Butterworths, London, 1990, p 278.

2 Gullet B.K., Ragnunathan K., Reduction of caoal-based metal emissiona by furnace sorbent injection, Energ Fuel 1994, 8, 1068-1076.

3 Ho T.C., Ghebremeskel A.N. and Hopper J.R., Trace metal capture by various sorbents during fluidised bed coal combustion, Am Chem Soc Div of Fuel Chem 1996, 41, 801-806.

4 Biswas P. and Wu Ch. Y., Control of toxic metal emissions from combustors using sorbents:A review, J Air Waste Manage 1998, 48, 113-127.

5 Jadhav R.A., Agnihotri R., Gupta H. and Fan L.S., Mechanism of selenium sorption by activated carbon, Can J Chem Eng 2000, 78, 168-174.

6 M. Díaz-Somoano Eliminación de elementos metálicos tóxicos de los productos de gasificación del carbón, PhD Thesis, Oviedo University (Spain), 2001.

7 Richaud R., Lachas H., Healey A.E., Redd G.P., Haines J., Mason P., Herod A.A., Dugwel D.R., and Kandiyoti R., Determination of 17 trace elements in coal and ash reference materials by ICP-MS applied to milligram sample sizes, Analyst 1999, $124,177-184$.

8 Richaud R., Lachas H., Healey A.E., Redd G.P., Haines J., Jarvis K.E., Herod A.A., Dugwell D.R., and Kandiyoti R., Trace element analysis of gasification plant samples by ICP-MS: Validation by comparison of results from two laboratories, Fuel 2000, 79, 1077-1087. 
9 Wu S., Zhao Y., Feng X. and Wittmeier A., Application of inductively coupled plasma mass spectrometry for total metal determination in silicon containing solid samples using the microwave-assisted Nitric Acid-Hydrofluoric Acid-Hydrogen Peroxide-Boric Acid digestion system, J Anal At Spectrom 1996, 11, 287-296.

10 Bettinelli M., Baroni U., Pastorelli N., Analysis of coal fly ash and environmental materials by inductively coupled plasma atomic emission spectrometry: comparison of different decomposition procedures, J Anal Atom Spectrom 1987, 2, 485-489.

11 S. Fadda, A. Rivoldiniand and I. Cau, ICP-MS determination of 45 trace elements in whole coal using microwave oven acid digestion for sample preparation, Geostandard Newslett 1995, 19, 41-54.

12 Rodushkin I., Axelsson M.D., Burman E., Multielement analysis of coal by ICP techniques using solution nebulization and laser ablation, Talanta 2000, 51 743-759.

13 Hon P.K., Lau O.W., Cheung W.C. and Wong M.C., The atomic absorption spectrometric determination of arsenic, bismuth, lead, antimony, selenium and tin with a flame-heated silica T-tube after hydride generation, Anal Chim Acta 1980, $115,355-359$.

14 Hon P.K., Lau O.W., and Tsui S.K., Determination of arsenic and antimony by hydride generation atomic absorption spectrometry using a small hydride generator, J Anal Atom Spectrom 1986, 1, 125-130.

15 ASTM, Standard test method for arsenic and selenium determination in coal by the hydride generation/atomic absorption method, ASTM, D4606-86, re-approved 1991.

16 Wolf R.E., and Grosser Z.A., Overview and comparison of ICP-MS methods for environmental analyses, Atom Spectrosc 1987, 18, 145-151. 
17 Zhang L.S., and Combs S.M., Using the installed spray chamber as a gas-liquid separator for the determination of Germanium, Arsenic, Selenium, Tin, Antimony, Tellurium and Bismuth by Hydride Generation Inductively Coupled Plasma Mass Spectrometry, J Anal Atom Spectrom 1996, 11, 1043-1048.

18 Hall G.E.M., and Pelchat J.C., Analysis of geological materials for Bismuth, Antimony, Selenium and Tellurium by Continuous Flow Hydride Generation Inductively Coupled Plasma Mass Spectrometry. Part 1. Mutual Hydride interferences, J Anal Atom Spectrom 1997, 12, 97-102.

19 Hall G.E.M., and Pelchat J.C., Analysis of geological materials for Bismuth, Antimony, Selenium and Tellurium by Continuous Flow Hydride Generation Inductively Coupled Plasma Mass Spectrometry. Part 1. Methodology and Results, J Anal Atom Spectrom 1997, 12, 103-106. 